\title{
Selective recombination close to the semi-dwarfing locus through bulk- population in the hybrid between Triticum aestivum and Triticum polonicum
}

\section{$\bowtie$ Md. Anowarul Haque}

School of Agriculture and Rural Development, Bangladesh Open University, Gazipur- 1705

\begin{tabular}{|c|c|}
\hline ARTICLE INFO OPEN & \\
\hline $\begin{array}{l}\text { eceived : } 06 \text { March } 2019 \\
\text { ccepted : } 14 \text { May } 2019 \\
\text { lblished: } 30 \text { June } 2019\end{array}$ & \multirow{3}{*}{ 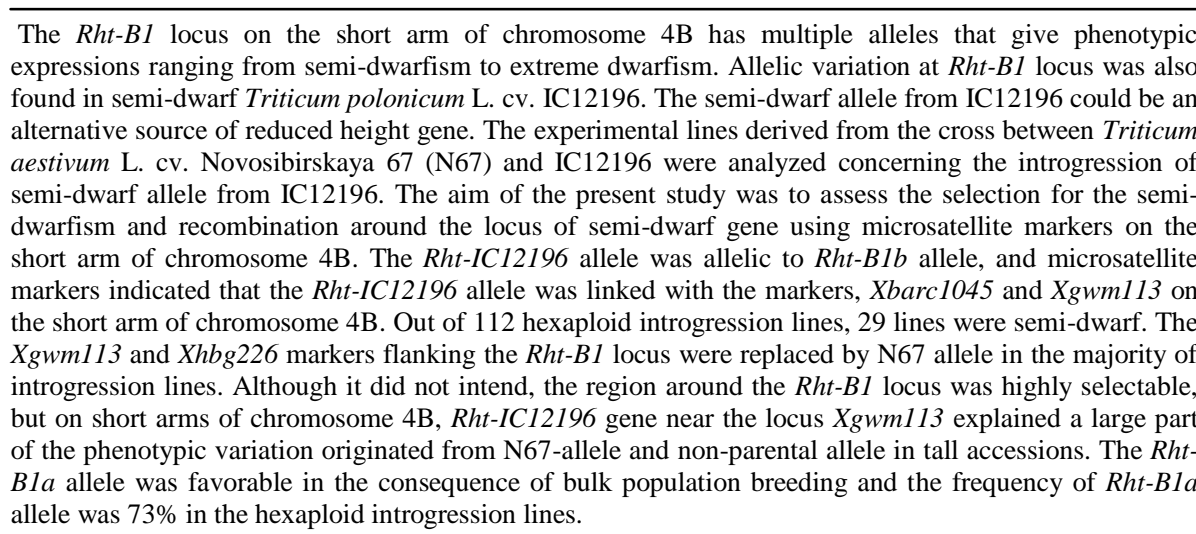 } \\
\hline & \\
\hline & \\
\hline
\end{tabular}

\section{Introduction}

A number of current wheat cultivars possess the genes for semi-dwarfism, Rht-Blb (Rht1) and Rht-Dlb (Rht2), originating from Triticum aestivum L. cv. Norin 10. They are commonly associated with increased yields in bread wheat (Perry and D'Antuono 1989) and in durum wheat (Waddington et al., 1987). Height reductions associated with attributed to a shorter yet stronger culm that accommodates high yields and prevents lodging in favourable environments (Ellis et al., 2004; Chapman et $a l$. 2007). The utilization of the Rht genes in many open public as well as personal reproduction applications changed higher cultivars through shorter ones (Richards, 1992).The Rht-Bl and Rht-Dl loci are contained in the most widely utilized semi-dwarf wheat cultivars. The Rht-B1 locus on the short arm of chromosome 4B and Rht-D1 locus on the short arm of chromosome 4D have multiple alleles that give phenotypic expressions ranging from semi-dwarfism to extreme dwarfism (Börner et al., 1996). Allelic variants at the Rht-Bl locus were found in common wheat (Worland, 1986; Worland and Petrovic 1988; Worland and Sayers, 1995), in T. aethiopicum Jakubz. (Börner et al. 1996), and also in Triticum polonicum L. cv. IC12196 (Watanabe, 2004).

It is interesting that the semi-dwarf allele of $T$. polonicum might be an alternative source of reduced height gene. Kang et al. (2009) were produced a synthetic hexaploid between $T$. polonicum collected in the region of Xinjiang, China, whose plant height was semi-dwarf, and Aegilops tauschii Coss., the D-genome progenitor of common wheat. Kosuge et al. (2010) suggested that hybridization of $T$. aestivum 'Novosibirskaya 67'- Triticum polonicum L. $(2 \mathrm{n}=4 \mathrm{x}=$ 28 , BBAA genome) 'IC12196' can rapidly give rise to a new landrace due to selective introgression of the $P$ gene for long glumes. IC12196 is characterized by semidwarfism and long glumes (Watanabe, 2004). The aim of the present study was to assess the selection and recombination for the semi-dwarfism in the progenies between $T$. aestivum and $T$. polonicum using microsatellite markers on the short arm of chromosome $4 \mathrm{~B}$.

\section{Materials and Methods}

\section{Plant materials}

To map the $\mathrm{GA}_{3}$-insensitive semi-dwarf gene, tentatively designated as Rht-IC12196, and microsatellite markers on chromosome $4 \mathrm{BS}$, produced $\mathrm{F}_{2}$ hybrid of T. aestivum 'Novosibirskaya 67 (N67)' - T. polonicum 'IC12196' and $\mathrm{F}_{2}$ hybrids of T. polonicum 'IC12196'/Triticum durum Desf. 'LD222'. Plant height of LD222 was tall. To investigate the allelic relationship between Rht-IC12196 and Rht-Blb alleles, $\mathrm{F}_{2}$ hybrids of $T$. polonicum 'IC12196'/T. durum 'Cando' were also obtained. Cando has the Rht-Blb allele derived from 
Norin 10. Using the $F_{2}$ generation of N67/IC12196, a small-scale bulk breeding method was applied to develop introgression lines. The procedure was described by Kosuge et al. (2010). Two hundred $\mathrm{F}_{2}$ plants were grown in an area of $20 \mathrm{~m}^{2}$. All the seeds were harvested from the $F_{2}$ plants as a bulk. Subsequently, $200 \mathrm{~F}_{3}$ seeds were randomly chosen from the bulk, and were grown in the same area size in the subsequent cropping cycle. This method was applied until reaching the bulked $F_{6}$ generation. Single seed descents of $132 \mathrm{~F}_{6}$ plants were used to advance the population from $\mathrm{F}_{7}$ through $\mathrm{F}_{10}$ generation. One-hundred and twelve hexaploid $F_{10}$ lines were available for the present experiment. All populations were grown in the experimental field at the College of Agriculture, Ibaraki University, Japan. Culm lengths of individuals were measured after ripening.

Microsatellite mapping of the Rht-IC12196 and allelic composition of the experimental lines

An intended to map of Rht-IC12196 using the $\mathrm{F}_{2}$ hybrid of N67/IC12196. However, it was found that segregation for plant height showed irregularity, probably due to aneuploidy in the $F_{2}$ generation. The chromosome numbers of the $\mathrm{F}_{2}$ of $\mathrm{N} 67 / \mathrm{IC} 12196$ was expected to vary from $2 n=28$ to 42 , depending on the transmission of the D-genome univalents (Alston and Jones, 1968). Alternatively, there are used $\mathrm{F}_{2}$ hybrids of IC12196/LD222 to establish a template linkage map of chromosome 4BS including the semi-dwarf locus. It was expected that the ratio of IC12196 and non-IC12196 (N67 and non-parental) allele at the given locus would be $1: 1$ in the $F_{10}$ generation provided there was lower natural selection during segregating generations. It was supposed non-parental allele was caused by a spontaneous mutation at the given locus.

Genomic DNA was extracted from seedling leaves of N67, IC 12196, LD222, F 2 hybrids of IC12196/LD222 and 112 hexaploid introgression lines, according to Dellaporta et al. (1983). To map the Rht-IC12196 gene and allelic composition of the introgression lines, used the wheat $X g w m, X b a r c$ and $X h b g$ microsatellite markers located on chromosome 4BS. The $X g w m$ microsatellite markers were developed by Röder et al. (1998). The Xbarc and Xhbg microsatellite markers were available from Song et al., (2005) and Torada et al. (2006), respectively. The PCR conditions, electrophoresis of PCR products and detection of amplified fragments followed Kosuge et al. (2008). Multipoint linkage values were calculated using Map Manager QTX (Manly et al., 2001). Minimum LOD scores of $>3.0$ were used to develop the linkage map. The software calculated genetic distances in centiMorgans (cM) by applying the Kosambi (1944) mapping function.

\section{Results and Discussion}

Twenty-nine semi-dwarf and eighty three lines were hexaploid introgression lines (Table 1) and Fig. 1 shows the distribution of culm length of hexaploid introgression lines. In the consequence of introgression of reduced height gene from IC12196, culm length of 29 lines was $67-106 \mathrm{~cm}$. Culm length of tall introgression lines was comparable with N67 (Fig. 1). The transmission ratio $(27 \%)$ of semi-dwarf gene (RhtIC12196) was remarkably less than the ratio of the gene for long glume (P1) found by Kosuge et al. (2010), who obtained around 50\% of long-glumed introgression lines. Khalifa and Qualset $(1974,1975)$ found that the proportion of dwarf genotypes in the mechanical mixture and hybrid bulks was gradually decreased from generation to generation under the supposed intergenotypic competition between tall and dwarf genotypes in $T$. aestivum. It was expected that alleles closely linked to Rht-IC12196 allele may be eliminated. The percentage of the IC12196-allele around the RhtIC12196 locus was about 50\%.The reports suggested that intended selection was required to obtain more recombinants for semi-dwarfism.

Table 1. Number of tall and semi-dwarf introgression lines derived from the cross of N67/ IC12196

\begin{tabular}{|c|c|c|c|}
\hline \multirow[b]{2}{*}{$\begin{array}{c}\text { Chromosome number }{ }^{1)} \\
(2 \mathrm{n})\end{array}$} & \multicolumn{2}{|c|}{ Culm length } & \multirow[b]{2}{*}{ Total } \\
\hline & $\begin{array}{l}\text { Semi-dwarf } \\
(67-106 \mathrm{~cm})\end{array}$ & $\begin{array}{c}\text { Tall } \\
(115-154 \mathrm{~cm})\end{array}$ & \\
\hline 42 & 29 & 83 & 112 \\
\hline 28 & 3 & 3 & 6 \\
\hline Total & 32 & 86 & 118 \\
\hline
\end{tabular}

${ }^{1}$ Chromosome numbers of individual lines were derived from Kosuge et al. (2010).

Table 2. Distribution of allele type of 19 markers in semidwarf, hexaploid introgression lines

\begin{tabular}{|c|c|c|c|}
\hline \multirow{2}{*}{$\begin{array}{c}\text { Semi-dwarf } \\
\text { lines }\end{array}$} & \multicolumn{3}{|c|}{ Type of allele } \\
\hline & IC12196 & N67 & Non-parental \\
\hline 7029 & 10 & 2 & 7 \\
\hline 7041 & 8 & 8 & 3 \\
\hline 7018 & 6 & 7 & 6 \\
\hline 7001 & 5 & 12 & 2 \\
\hline 7007 & 4 & 9 & 6 \\
\hline 7009 & 4 & 15 & 0 \\
\hline 7011 & 4 & 14 & 1 \\
\hline 7022 & 4 & 13 & 2 \\
\hline 7025 & 4 & 13 & 2 \\
\hline 7037 & 4 & 14 & 1 \\
\hline 7060 & 4 & 10 & 5 \\
\hline 7069 & 4 & 12 & 3 \\
\hline 7088 & 4 & 14 & 1 \\
\hline 7104 & 4 & 11 & 4 \\
\hline 7120 & 4 & 11 & 4 \\
\hline 7051 & 3 & 12 & 4 \\
\hline 7075 & 3 & 12 & 4 \\
\hline 7078 & 3 & 12 & 4 \\
\hline 7085 & 3 & 12 & 4 \\
\hline 7097 & 3 & 15 & 1 \\
\hline 7012 & 2 & 15 & 2 \\
\hline 7039 & 2 & 16 & 1 \\
\hline 7050 & 2 & 15 & 2 \\
\hline 7117 & 2 & 16 & 1 \\
\hline 7118 & 2 & 14 & 3 \\
\hline 7125 & 2 & 14 & 3 \\
\hline 7028 & 1 & 17 & 1 \\
\hline 7033 & 1 & 18 & 0 \\
\hline 7127 & 1 & 16 & 2 \\
\hline
\end{tabular}




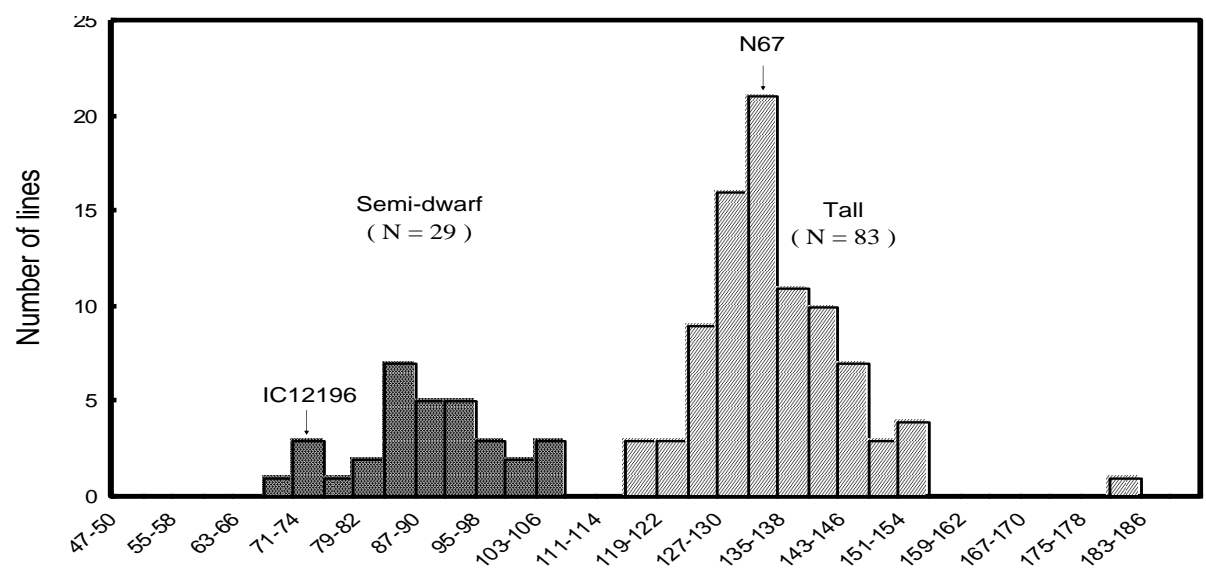

Culm length $(\mathrm{cm})$

Fig. 1. Distribution of culm length of introgression lines. Arrows indicate mean values of culm length; N67 $(132 \mathrm{~cm})$ and IC12196 $(74 \mathrm{~cm})$

Microsatellite mapping of the gene for Rht-IC12196

$\mathrm{F}_{1}$ hybrid between IC12196 and Cando was semi-dwarf. If the loci determining the culm length were different, the segregation would be expected to be 13 semi-dwarf: 3 tall in $\mathrm{F}_{2}$ progenies but any tall plants were not found in one hundred thirty $\mathrm{F}_{2}$ plants. It was confirmed that the semi-dwarf gene of IC12196 was allelic to Rht-B1b. The dominant alleles of IC12196 were temporarily designated as Rht-IC12196. $\quad \mathrm{F}_{2}$ hybrid of IC12196/LD222 was segregated for plant height (Fig. 1). Segregation of culm length (Table 1) fit a 3:1 ratio $\left(\chi^{2}=\right.$ 0.434 , df = 1). Rht-IC12196 was linked with markers, Xbarc1045 and Xgwml13 on chromosome 4BS (Fig. 2). Except for $X g w m 495\left(\chi^{2}=4.487, \mathrm{P}<0.05\right)$, segregation for five markers, Xbarc10145, Xhbg226, Xgwm113, $X w m c 48$ and Xwmc47, fitted 3: 1 ratios. The $\chi^{2}$ values ranged from 1.294 to $3.710(\mathrm{df}=1)$. An inaccurate genetic map of the region of Rht-Bl locus would modify the expected effects of recombination and linkage. Indeed, conflicting orders of markers in this Rht-Bl region reported in the ITMI reference map cited in Raquin et al. (2008) were not polymorphic around the Rht-B1 locus and covered a larger genetic distance.

Allelic composition in the short arm of chromosome 4B of N67/ IC 12196 introgression lines

The introgression lines were designated as IL 7001 to IL 7118 and focused on analysis of 112 hexaploid

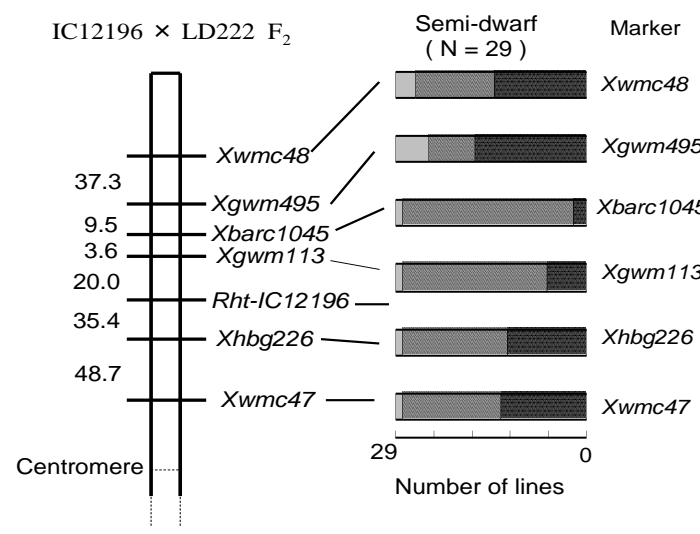

IC12196 introgression lines and their parents, N67 and IC12196. They were scored for allelic composition at the mapped and un-mapped marker loci on the short arm of chromosome 4B (Fig. 2). Right-handed side of Fig. 2 indicated the type of allele linked with mapped marker in semi-dwarf lines and tall lines. It was supposed that non-parental alleles were not caused by any mixture. Probably they were due to outcross with surrounding plots, because, early generations $\left(\mathrm{F}_{2}\right.$ and $\left.\mathrm{F}_{3}\right)$ were relatively sterile due to the presence of aneuploids. The short arms of chromosome 4B were replaced by N67allele and non-parental allele in tall accessions. In the great number of introgression lines, the Xgwm 113 and Xhbg226 markers flanking the Rht-Bl locus were replaced by N67-allele. It suggested that N67-alleles were more favorable than IC12196-alleles even in semidwarf introgression lines. In other words, tall phenotypes were more favorable than semi-dwarf ones during bulk breeding process, and N67-alleles were selectively saved in the progenies. However, the IC12196-alleles at proximal markers were not selective in both tall and semi-dwarf introgression lines.

Fig. 2. Linkage map of the short arm of chromosome $4 \mathrm{~B}$ (left-hand side) and the frequency of allele in hexaploid introgression lines (right- hand side) 
Allelic composition of individual introgression lines was summarized in Fig. 3. It was interesting that the frequency of N67-allele was high in un-mapped markers. The frequency of N67-alleles was higher than that of IC12196-allele in the markers flanking Rht-IC12196 allele. It suggested that the frequency of the semi-dwarf allele and flanking alleles was decreased during the breeding process. It seemed that the distances of Xgwm 113 and Xhbg226 markers to Rht-B1 locus (20.0 and $35.4 \mathrm{cM}$ ) were enough to promote recombination. Table 2 compared with semi-dwarf lines, the frequency IC12196-alleles in tall lines was less than 19\%. Stochasticity associated with linkage to other genes that are under selection is not the same as sampling error, and is sometimes known as genetic drift.

Strong selection within a given population locally reduces genetic variability not only in the selected gene itself but also in neighboring loci (Raquin et al., 2008). This effect is related to the initial linkage disequilibrium between markers and the selected gene. It depends mainly on the number of copies of the beneficial allele at the beginning of the selection phase (Raquin et al., 2008). Under a small-scale bulk breeding method, taller plants were favored against shorter plants determined by Rht-IC12196. Although I did not intend it, the region around the Rht-BI locus was highly selectable, and the Rht-Bla allele was favorable in the process of bulkpopulation selection. The frequency of Rht-Bla allele was $73 \%$ in the hexaploid lines. Except for the four introgression lines, 7029, 7041, 7018 and 7007, the

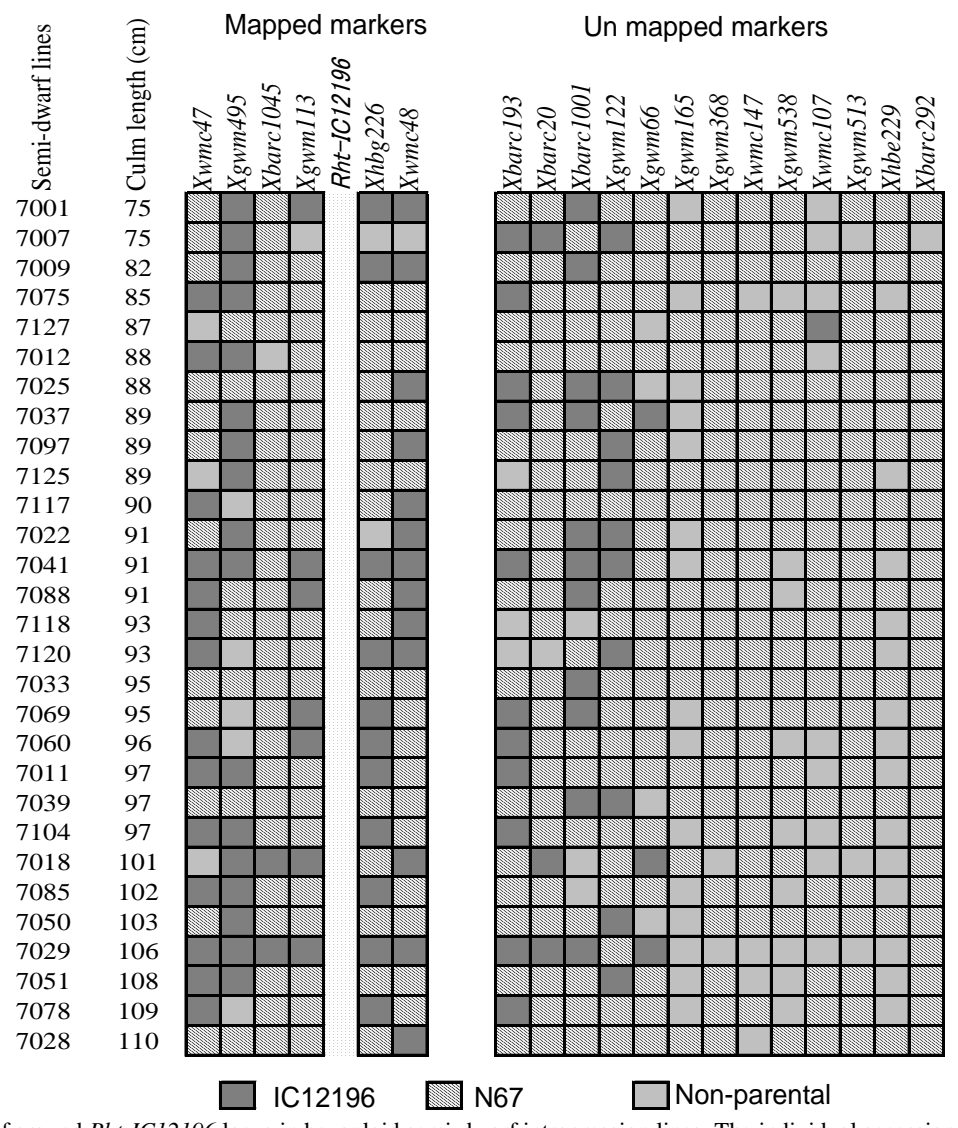

Fig. 3. Allelic composition of around Rht-IC12196 locus in hexaploid semi-dwarf introgression lines. The individual accessions were sorted by their culm length

frequency of N67-alleles is extremely low in the short arm of chromosome 4B. Erayman et al. (2004), Lukaszewski and Curtis (1993), See et al. (2006) and Sidhu and Gill (2004) informed the telomeric regions were occupied by the recombination of the chromosomes with a gradient from the centromeres to the telomeres in wheat. Erayman et al. (2004) revealed that $95 \%$ of the recombination occurs in 48 gene-rich regions covering $29 \%$ of the physical size of the wheat genome. Saintenac et al. (2009) observed that a dense reference genetic map comprising 102 markers homogeneously distributed together with the chromosome was compared to a physical deletion map. Most of the crossovers (90\%) occurred in the distal subtelomeric regions that illustrated fifty percent of the chromosome. A very weak crossover frequency was observed on the proximal regions nearby the centromere. Although there are need more polymorphic markers for further resolution, this experimental analysis indicated that the region around the Rht-Bl locus was highly selectable. The application of the bulk breeding method to introduce reduced height gene indicated not only the characteristics of recombination on the short arm of chromosome 4B, but also the relatively strong natural selection around Rht-BI locus. Thus, the allelic combination around Rht-IC12196 locus was dominated by N67-allele in the semi-dwarf introgression lines, which may be possible breeding materials. 


\section{Acknowledgement}

Md. Anowarul Haque deeply appreciates to Prof. Dr. Nobuyoshi Watanabe, Professor, Faculty of Agriculture, Ibaraki University, Japan for his supportive supervise and provided seeds of $\mathrm{F}_{9}$ introgression lines of N67/IC12196.

\section{References}

Alston, F.H. and Jones, J.K., 1968. Variation in transmission of univalent chromosomes from pentaploid wheat hybrid. Canadian Journal of Genetics and Cytology, 10: 908-912. https://doi.org/10.1139/g68-113

Börner, A., Plaschke, J., Korzun, V. and Worland, A.J., 1996. Relationship between the dwarfing genes of wheat and rye. Euphytica, 89: 69-75. https://doi.org/10.1007/BF00015721

Chapman, S.C., Mathews, K.L., Trethowan, R.M., Singh, R.P., 2007. Relationships between height and yield in near-isogenic spring wheats that contrast for major reduced height genes. Euphytica. 157: 391-397. https://doi.org/10.1007/s10681006-9304-3

Dellaporta, S.L., Wood, J. and Hicks, J.B., 1983. A plant DNA minipreparation: Version II. Plant Molecular Biology Reporter, 1: 19-21. https://doi.org/10.1007/BF02712670

Ellis, M.H., Rebetzke, G.J., Chandler, P., Bonnett, D., Spielmeyer, W., Richards, R.A., 2004. The effect of different height reducing genes on the early growth of wheat. Functional Plant Biology, 31: 583-589. https://doi.org/10.1071/FP03207

Erayman, M., Sandhu, D., Sidhu, D., Dilbirligi, M. and Baenzigeret PS et al., 2004. Demarcating the gene-rich regions of the wheat genome. Nucleic Acids Research, 32: 546-3565. https://doi.org/10.1093/nar/gkh639

Kang, H.-Y., Wang, Y., Yuan, H.-J., Jiang, Y. and Zhou, Y.-H., 2009. Production of intergeneric hybrid between dwarfing Polish wheat (Triticum polonicum L.) and Aegilops tauschii Cosson. with reference to wheat origin. Russian Journal of Genetics, 45: 671-677. https://doi.org/10.1134/S1022795409060064

Khalifa, M.A. and Qualset, C.O., 1974., Intergenotypic competition between tall and dwarf wheats. I. In mechanical mixtures. Crop Science, 14: 795-799. https://doi.org/10.2135/cropsci1974.0011183X0014000600 $05 \mathrm{x}$

Khalifa, M.A. and Qualset, C.O., 1975. Intergenotypic competition between tall and dwarf wheats. II. In hybrid bulks. Crop Science, 15 : 640-644. https://doi.org/10.2135/cropsci1975.0011183X0015000500 $10 \mathrm{x}$

Kosambi, D.D., 1944. The estimation of map distances from recombination values. Annals of Eugenics. 12:172-175. https://doi.org/10.1111/j.1469-1809.1943.tb02321.x

Kosuge, K., Watanabe, N. and Kuboyama, T., 2010. Recombination around the $\mathrm{P}$ locus for long glume phenotype in experimental introgression lines of Triticum aestivum Triticum polonicum. Genetic Resources and Crop Evolution, 57:611-618. https://doi.org/10.1007/s10722009-9499-y

Kosuge, K., Watanabe, N., Kuboyama, T., Melnik, V.M., Yanchenko, V.I., Rosova, M.A. and Goncharov, N.P., 2008. Cytological and microsatellite mapping of mutant genes for spherical grain and compact spikes in durum wheat. Euphytica, 159: 289-296. https://doi.org/10.1007/s10681-007-9488-1

Lukaszewski, A. and Curtis, C.A., 1993. Physical distribution of recombination in $\mathrm{B}$-genome chromosome of tetraploid wheat. Theoretical and Applied Genetics, 86: 121-127. https://doi.org/10.1007/BF00223816

Manly, K.F., Cudmore, R.H. Jr, Meer, J.M., 2001. Map Manager QTX, cross-platform software for genetic mapping. Mammalian Genome.12(12): 930-2. https://doi.org/10.1007/s00335001-1016-3

Perry, M.W. and D'Antuono, M.F., 1989. Yield improvement and associated characteristics of some Australian spring wheat cultivars introduced between 1860 and 1982. Australian Journal of Agricultural Research, 40: 457-472. https://doi.org/10.1071/AR9890457

Raquin, A.-L., Brabant, P., Rhoné, B., Balfourier, P. Leroy and Goldringer, I., 2008. Soft selective sweep near a gene that increases plant height in wheat. Molecular Ecology, 17: 41756. https://doi.org/10.1111/j.1365-294X.2007.03620.x

Richards, R.A., 1992. The effect of dwarfing genes in spring wheat in dry environments. II. Growth, water use and water use efficiency. Australian Journal of Agricultural Research, 43: 529-539. https://doi.org/10.1071/AR9920529

Röder, M.S., Korzun, V., Wendehake, K., Plaschke, J., Tixier, M.-H., Leroy, P. and Ganal, M.W., 1998. A microsatellite map of wheat. Genetics, 149: 007-2023.

Saintenac, C., Falque, M., Martin, O.C., Paux, E., Feuillet, C. and Sourdille, P., 2009. Detailed Recombination studies along chromosome 3B provide new insights on crossover distribution in wheat (Triticum aestivum L). Genetics, 108: 393-403. https://doi.org/10.1534/genetics.108.097469

See, D.R., Brooks, S., Nelson, J.C., Brown-Guedira, G. and Friebe, B. et al., 2006. Gene evolution at the ends of wheat chromosomes. Proceedings of the National Academy of Sciences of the United States of America, 103: 162-4167. https://doi.org/10.1073/pnas.0508942102

Sidhu, D. and Gill, K.S., 2004. Distribution of genes and recombination in wheat and other eucaryotes. Plant Cell, Tissue and Organ Culture, 79: 257-270. https://doi.org/10.1007/s11240-005-2487-9

Song Q.J., Shi, J.R., Singh, S., Fikus, E.W., Costa, J.M., Lewis, J., Gill, B.S., Ward, R. and Cregan, P.B., 2005. Development and mapping of microsatellite (SSR) markers in wheat. Theoretical and Applied Genetics, 110: 550-560. https://doi.org/10.1007/s00122-004-1871-X

Torada, A., Koike, M., Mochida, K. and Ogihara, Y., 2006. SSR-based linkage map with new markers using an intraspecific population of common wheat. Theoretical and Applied Genetics, 112: 1042-1051. https://doi.org/10.1007/s00122006-0206-5

Waddington, S.R., Osmanzai, M., Yoshida, M. and Ransom, J.K., 1987. The yield of durum wheats released in Mexico between 1960 and 1984. Journal of Agricultural Science Cambridge, 108: 469-477. https://doi.org/10.1017/S002185960007951X

Watanabe, N., 2004. Triticum polonicum IC12196: a possible alternative source of $\mathrm{GA}_{3}$-insensitive semi-dwarfism. Cereal Research and Communication, 32: 29-434.

Worland, A.J. and Petrovic, S., 1988. The gibberellic acid insensitive dwarfing gene from the variety Saitama 27. Euphytica, 38: 55-63. https://doi.org/10.1007/BF00024811

Worland, A.J. and Sayers, E.J., 1995. Rht1 (B. dw), an alternative allelic variant for breeding semi-dwarf wheat varieties. Plant Breeding, 114: 397-400. https://doi.org/10.1111/j.1439-0523.1995.tb00819.x

Worland, A.J., 1986. Gibberellic acid insensitive dwarfing genes in southern European wheats. Euphytica, 35: 857-866. https://doi.org/10.1007/BF00028593 